\title{
KELEA (Kinetic Energy Limiting Electrostatic Attraction) Can Markedly Improve the Performance of Gasoline and Diesel Fuels in Power Generation and in Transportation
}

\author{
W. John Martin \\ Institute of Progressive Medicine, South Pasadena, USA \\ Email: wjohnmartin@ccid.org
}

Received 30 March 2016; accepted 23 April 2016; published 26 April 2016

Copyright (C) 2016 by author and Scientific Research Publishing Inc.

This work is licensed under the Creative Commons Attribution-NonCommercial International License (CC

BY-NC).

http://creativecommons.org/licenses/by-nc/4.0/

(c) (i) (9) Open Access

\section{Abstract}

The combustion (burning) of hydrocarbon fuels comprises oxygen mediated breaking of the carbon to carbon and carbon to hydrogen chemical bonds, leading to the formation of oxygen to carbon and oxygen to hydrogen bonds; primarily as carbon dioxide and water, respectively. The oxygen gas molecules yield considerable energy during the conversion to carbon and hydrogen bound oxygen atoms. The net energy derived from hydrocarbon combustion is normally regarded as being fully converted into heat, as a form of kinetic energy. In industrial processes, some of the resulting heat is used to raise the temperature of other materials, including water for power generation. Combustion derived heat is also used to provide a localized increase in kinetic energy (pressure) of gaseous molecules that can be directly converted into mechanical work. This is the principle of combustion driven transportation and many other power generating engines. An emerging concept is that fluids can also possess a transferrable form of kinetic energy that is unrelated to heat. This newly proposed fluid associated, non-thermal kinetic energy is derived from the environment force termed KELEA (Kinetic Energy Limiting Electrostatic Attraction). KELEA results in the loosening of the hydrogen bonding between liquid molecules and probably also imparts added motion to the molecules. It is proposed that this added non-thermal kinetic energy is carried over into the combustion products, which can consequently yield increased mechanical work. KELEA also seemingly allows for more complete combustion with reduced levels of unburnt hydrocarbons. KELEA activation of liquid fuels can be accomplished using KELEA attracting and transmitting compounds, including activated fluids, either added into or placed in close proximity to the fuel. KELEA activation of fuels, including gasoline and diesel, provides a simple method to significantly improve the efficiency of their use in power generation and in transportation. The studies are relevant to reducing the current worldwide levels of hydrocarbon usage and environmental pollution. 


\section{Keywords}

\section{Kiko, Mojo, Gasoline, Diesel, Combustion, KELEA, Kinetic Energy, Soliton, Climate Change}

\section{Introduction}

Water has long been known to possess unusual characteristics compared to other liquids, which render it particularly suitable for facilitating chemical reactions, and indeed for supporting all forms of life [1]. Less well appreciated is that even highly purified water may display differences in certain of these important characteristics, including surface tension, viscosity, boiling and freezing temperatures, vapor pressure and specific heat [2]. These differences are best explained by variable strength of the hydrogen bonding between the water molecules, together with increased kinetic activity of the loosened molecules. A series of ongoing studies are consistent with the loosening of the intermolecular hydrogen bonding due to the absorption of an environmental force termed KELEA (Kinetic Energy Limiting Electrostatic Attraction). The role of this fundamental force is presumed to prevent the fusion and possible annihilation of opposite electrical charges. It may also provide the repulsion force between identical electrical charges [2] [3].

While regular water may not directly attract KELEA from the normal environment, it can be transferred to water using certain dipolar chemical compounds with separated electrical charges, possibly in an oscillatory manner [4]. It can also be transferred to nearby water using various electrical devices, principally with rapid on-off switching [5] [6]. Once water is sufficiently activated, its separated electrical charges can then attract KELEA leading to further activation, including the activation of added water. This principle explains homeopathy [7]. KELEA activated compounds and water can also provide an energy field able to activate nearby water without the need for direct contact [8].

KELEA activation can be shown with other fluids, including ethanol and gasoline [3]. It can act on fluids in both the liquid and vapor states. Evidence has been provided in previous publications for health, agriculture and industrial benefits of using KELEA activated water [9]-[11]. The present paper is to demonstrate that the benefits of KELEA activation can extend to significantly increasing the efficiency of gasoline and diesel fuels in transportation. In addition to increased mileage, the data indicate a more complete combustion of the hydrocarbons to carbon dioxide $\left(\mathrm{CO}_{2}\right)$, with lower levels of carbon monoxide (CO) and unburnt hydrocarbons (UHC). This finding has relevance to global warming and to potential adverse health effects of UHC.

\section{Materials and Methods}

Kiko Technology (www.kikotechnology.org) comprises the use of finely ground, mined volcanic rock material. The powdered material is suspended in water droplets that are dried to form small pellets. The pellets are then subjected to several rounds of heating and cooling. The Kiko pellets can either be used alone or placed into cartridges with perforations allowing for the flow of fluids. The cartridges measure $20 \mathrm{~mm} \times 128 \mathrm{~mm}$ with multiple $2 \mathrm{~mm}$ perforations and contain $\sim 50$ pellets ranging from $3-6 \mathrm{~mm}$ diameter and weigh a total of $\sim 22.5 \mathrm{gm}$. Two cartridges are suitable for large storage tanks of either gasoline or diesel. Individual pellets are more suitable for either adding directly to the gas tank of vehicles, or for activating a quantity of fuel prior to its transfer to mix with the fuel already within the vehicle. Magnesium oxide granules from which the finer particles are removed by decanting can similarly be used (3), as can many other fluid activating dipolar compounds or fluids.

Gas Mojo is a commercially available fuel-saving device (www.gasmojo.com). One model comprises a 6 inch-long by 1 inch-diameter sealed polyvinyl chloride tube containing activated water (www.gasmojo.com). The device is simply zip-tied to a section of the vehicle's fuel line. The exact mechanism of water activation is proprietary, but many procedures are now available for KELEA activation of fluids. Several Gas Mojo devices, as well as alternative packaging of activated fluids, were provided by the manufacturer for research studies.

Fuel consumption. For automobiles, the major measure is the distance traveled per liter or per gallon of gasoline. For industrial machinery, the daily consumption of diesel withdrawn from a 10,000-gallon diesel storage tank, required in performing a set amount of work, was measured before and after the addition of two Kiko cartridges.

Fuel burning emission analysis. The percentage of $\mathrm{CO}_{2}$ and $\mathrm{CO}$ and the UHC concentration in the vehicle's 
exhaust were measured at licensed motor testing centers in Hong Kong and in Switzerland.

Surface Tension. Measurements of surface tension were made on diesel before and after exposure to Kiko pellets using a Du Nouy Tensionmeter (Itoh Seisakusho Ltd., Tokyo, Japan).

\section{Results}

The normal fuel consumption rates of six different types of automobiles were repeatedly determined at various times over periods of at least 3 months in 2015. Six Kiko pellets were then inserted into the fuel tank of each of the automobiles. The fuel consumption rates were repeatedly measured after the addition of the Kiko pellets. The before and after Kiko mileage values, expressed as kilometers per liter $(\mathrm{km} / \mathrm{l})$ are summarized in Table 1 . The benefits ranged from $10 \%$ to $43 \%$ increases in fuel efficiency. The improved mileage observed in each of the automobiles has continued through to the present time (March 2016).

As an alternative to adding Kiko pellets to the automobile's fuel tank, the pellets can be added to a relatively small quantity of gasoline, which is subsequently added to the existing fuel in the automobile. Typically, 1 to 4 liters of gasoline are exposed to the pellets for several hours prior to the transfer of the gasoline into the car's nearly filled fuel tank. This approach also resulted in improved gas mileage and avoids regulatory restrictions to adding non-certified materials to an automobile's fuel tank. The exhaust gases of two automobiles were tested before and after the addition of 1 liter of Kiko activated fuel to the existing fuel in the automobiles. Significant reductions in $\mathrm{CO}$ and $\mathrm{UHC}$ were seen with both tests, with essentially unchanged $\mathrm{CO}_{2}$ levels (Table 2).

Another alternative to avoiding the regulatory obstacle of adding materials to gasoline is to attach a 6-inch container of activated water in sealed polyvinyl tubing to either the external gas tank or to the fuel line. This method has been promoted by Dearborn Corporation, Illinois and marketed under the name Gas Mojo. Devices have been installed on several hundred automobiles and on numerous trucks, leading to a minimal improved mileage of approximating $20 \%$ and sometimes reaching over $40 \%$. Particularly notable is the reduced idling speed of the engines (typically around 25\% e.g. $1000 \mathrm{rpm}$ reduced to $750 \mathrm{rpm}$ ) and the slower speeds at which the transmission shifts from lower to a higher gear (e.g. by about $5 \mathrm{mph}$ ). Another observation is faster acceleration, for example a diesel truck required 11.7 seconds to accelerate 0 - $60 \mathrm{mph}$. After installing the Gas Mojo, the same truck required only 7.4 seconds (duplicate readings). A marked reduction in both the smoky appearance and the smell of diesel exhaust is consistently observed in trucks with an installed Gas Mojo device.

Table 1. Mileage in kilometers per liter $(\mathrm{km} / \mathrm{l})$ before and after exposure to Kiko pellets.

\begin{tabular}{cccc}
\hline Vehicle & Before Kiko & After Kiko & Increased \% mileage \\
\hline Toyota Camry & 5.8 & 8.3 & 43 \\
KIA Optima & 8.3 & 9.1 & 10 \\
Honda Civic & 10.0 & 12.9 & 29 \\
BMW 323 i & 9.1 & 10.9 & 20 \\
BMW X5 SUV & 7.1 & 9.1 & 28 \\
Austin Mini & 9.3 & 11.4 & 23 \\
\hline
\end{tabular}

Table 2. Exhaust gas emission by volume before and after exposure to Kiko pellets.

\begin{tabular}{|c|c|c|c|}
\hline \multicolumn{4}{|c|}{ Mitsubishi } \\
\hline Emission & Before Kiko & After Kiko & \% Reduction \\
\hline Percentage $\mathrm{CO}_{2}$ & 14.1 & 14.6 & -3.55 \\
\hline Percentage CO & 0.341 & 0.035 & 89.7 \\
\hline ppm UHC & 197 & 67 & 66.0 \\
\hline \multicolumn{4}{|c|}{ Volkswagen } \\
\hline Percentage $\mathrm{CO}_{2}$ & 15.1 & 15.2 & -0.07 \\
\hline Percentage CO & 0.10 & 0.04 & 60.0 \\
\hline ppm UHC & 30 & 14 & 53.3 \\
\hline
\end{tabular}


The benefits seen with Kiko, Gas Mojo and comparable devices with gasoline and diesel fuels in cars and trucks can also be obtained with farm machinery. For example, two Kiko cartridges, each containing approximately 50 pellets were placed in a 10,000 gallon above ground diesel storage tank. A John Deere Model 7760 cotton harvester would fill from the tank on a daily basis. Prior to adding the Kiko cartridges, the harvester required 378 gallons for an 8-hour day harvesting. With Kiko activated diesel, the harvester only needed 288 gallons of diesel a day, a $26 \%$ fuel saving. A water pivot used for irrigating the cotton fields also required $10 \%$ less fuel when using activated diesel to maintain the daily operation.

Another measurable difference between activated and regular diesel is the reduction in surface tension. For example, in repeated experiments, Kiko pellets reduced the surface tension of diesel from 31 dynes per $\mathrm{cm}^{2}$ to 16 dynes per $\mathrm{cm}^{2}$, representing a $16 \%$ reduction.

\section{Discussion}

The present results will be discussed mainly in the context of how they may relate to the evolving concept of KELEA. This concept may also help explain earlier anecdotal reports of enhanced fuel efficiency. While further experimental studies are clearly necessary, the hypothesis presented in this paper may help stimulate research towards a new understanding of energy pathways.

Since the early 2000's, several individuals have communicated to the author that they were able to significantly increase the gasoline mileage of their automobiles. A notable example was the distributer of an agricultural enhancement formulation called HB-101. Beginning in 2001, he would regularly add $100 \mathrm{ml}$ of HB-101 to his 2001 Toyota Camry (18.5-gallon, 70-liter fuel tank). At 1:700 dilution, the added HB-101 consistently enabled him to achieve approximately $25 \%$ improvement in mileage on his numerous trips to visit rural customers. HB-101 is rich in dipolar terpenes and is one of the earlier products studied by the author for the property of enhancing the biological activity of water. This property has since been shown to be due to the attracting and transferring of KELEA into water. The water activating activity of HB-101 explains its marked agricultural enhancing benefits even when used at 1:10,000 dilution in irrigation water (www.hb-101.com). Another notable early example noted by the author was the more effective combustion of gasoline by using magnesium particles, with or without HB-101 added to gasoline [12]. The magnesium particles were initially intended to generate hydrogen gas. Subsequent studies indicated that hydrogen can also attract KELEA into fluids. Hydrogen and oxygen gases are produced during the electrolysis of water. Electrolysis can also generate a vapor of highly activated water. This can be seen as a stream of bubbles developing midway between the electrodes. The combination of hydrogen, oxygen and vaporized activated water is referred to as Brown's gas and sometimes as HHO. Water electrolysis devices have been widely used as an attachment to vehicles to increase the engine's performance [13]-[15]. Although it had been assumed that the Brown's gas was acting directly as a combustion fuel, the author has favored the notion that the primary action of Brown's gas in automobiles is that of gasoline activation. This opinion was derived by working with major manufacturers of Brown gas generating devices marketed on the internet (e.g. watertogas.com). A basis for the author's opinion is that the added performance of the gasoline far exceeds the direct contribution provided by the combustion of the Brown's gas. Moreover, gasoline can be activated using Brown's gas prior to the gasoline being added to the fuel tank and long after the added Brown's gas has dissipated (unpublished). Similarly, water remains activated well after the infusion of hydrogen and/or Brown's gas (unpublished).

The new data included in this paper indicate that fuel activation can be similarly accomplished by both the addition of KELEA activating volcanic rock pellet to a portion of the fuel and the placement of activated water into close proximity to the fuel line. These two approaches are comparable to methods currently being used to activate water for human consumption. Thus, as with homeopathy, only a portion of the total fluid needs to be directly activated. If sufficiently activated, the separated electrical charges in activated fluids can attract and transmit KELEA to larger volumes of added fluids. Activated water can also transmit energy to regular water without requiring direct contact with the latter. This concept was initially utilized by Johann Grander in a water activating device in which water was simply allowed to flow in close proximity to activated water, but without making actual contact (www.granderwater.co.uk). Avoiding direct contact of components with fuel has the regulatory advantage of not requiring a waiver on the general prohibition against adding non-certified materials to fuel. The use of Kiko pellets and the Gas Mojo device also have the benefit over Brown's gas delivery devices of working even when the vehicle is not running. 
Although the various procedures used to markedly increase gas mileage are different, there is a striking similarity in many of the reported additional benefits. These include lower idling speed and lower engine speeds (rpm) required for upward gear shifting. The automobiles and especially large trucks clearly have more power in addition to the remarkably improved fuel economy. Thus, trucks can climb hills faster and often remain in a higher gear after installing a fuel saving device. Even more striking, is the consistent reports that the engines run cooler, in spite of seemingly increased efficiency of combustion. This observation runs counter to the assumption that pressure, volume and temperature values of gases conform to set ratios, as defined by the Ideal Gas Law [16]. As published earlier, KELEA activation increases the volatility of ethanol [3]. When the resulting ethanol vapor is confined, it achieves a far greater pressure at a given temperature than the vapor from nonactivated ethanol. Since pressure is a measure of kinetic energy, this finding essentially indicates a form of nonthermal kinetic energy. KELEA is a repulsive force that acts on electrical charges. It may, therefore, restrict intermolecular collisions between vapor molecules, the presumed source of heat. The non-thermal kinetic energy is, nevertheless, seemingly able to do mechanical work, such as moving the pistons within an engine.

Although yet to be confirmed experimentally, the premise of this paper is that additional KELEA contained within the liquid fuel is being transferred to the vapor fuel and to the fuel combustion products. One possibility is that the acquired non-thermal kinetic activity comprises moving solitons, which are able to exert force but without having any accompanying friction [17]. Whatever its form, the proposed non-thermal kinetic energy allows for the combustion products of activated fuels to achieve more mechanical work than the combustion products of regular fuel at the same temperature. Stated differently, KELEA increases the ratio of work output to combustion temperature and in turn significantly increases the efficiency of fuel usage. The effect is quite striking and in the range of easily achievable $20 \%$ - 30\% improved fuel efficiency.

While the above hypothesis is the most tantalizing for the importance of urgently needed further studies, there are likely to be additional minor reasons for improved efficiency of KELEA activated fuels. A relatively small but very important measure of the energetic improvement is the more complete combustion of the hydrocarbons. This is seen as reduced CO and UHC levels in the exhaust of automobiles and in the elimination of black smoke and malodor from diesel exhausts. UHC is deemed toxic for individuals, animals and plant life and its reduction in clearly beneficial for health reasons. A possible contributing factor to the more complete combustion may be the lowered surface tension of the activated fuels. It is known, for example, that added devices, which allow for the pre-vaporization of gasoline, can result in more complete gasoline combustion

(http://fuel-efficient-vehicles.org/energy-news/?page_id=968). This implies that some of the fuel ordinarily introduced into car cylinders is still in a liquid (droplet) form. As with activated water, the droplet size of condensing KELEA activated gasoline is smaller than that of condensing regular gasoline. The smaller droplets in the activated fuel will likely vaporize faster than the droplets in regular fuels and, thereby, have greater contact with oxygen prior to combustion. Finally, a reduced piston friction could also be contributing to heat reduction. It is difficult, however, to envision how these factors, even collectively, could achieve the rather remarkable $20 \%-30 \%$ increases in overall fuel efficiency, described in this article. Indeed, this may still be a lower range since additional improvements in fuel efficiencies may be available through adjustments to the air/fuel supply and ratio.

As will be described elsewhere, KELEA activated gasoline can assist in the removal of preformed engine carbon deposits and can help prevent metal corrosion within fuel lines. This benefit is similar to the removal of scale and limiting of corrosion seen when using KELEA activated water in heat exchangers [11]. Activated gasoline may also have a distant effect on other fluids within the vehicles. It may, for example, increase the fluidity of transmission fluids. This is suggested by the noticeable smoother transmissions experienced in cars fitted with the Gas Mojo device (www.gasmojo.com). Potentially this benefit will lead to less likelihood of the need for future transmission repairs.

There are many opportunities for using KELEA activated fuels in various industrial and domestic applications. Prominent examples include shipping, trains, aviation, farm equipment, electricity generators, cranes, lawn mowers. KELEA activation can also be applied to various fuels beyond gasoline and diesel, including ethanol, natural gas and propane gas. It is generally advantageous to activate fuels at the locations of their eventual uses, since earlier activation can potentially lead to increase losses from the greater volatility of the activated fuels [3]. There is a major overlap between methods of activating water for drinking, agricultural and industrial purposes and the activation of fuels. Many of these methods have only minimal costs and yet can potentially yield enormous savings and other benefits. 


\section{Conclusion}

The capacity of gasoline and diesel fuels to provide mechanical work for transportation and for power generation can be increased by KELEA (Kinetic Energy Limiting Electrostatic Attraction). This energy can be transmitted to fuels using various KELEA attracting compounds and energy fields. KELEA activation also allows for more complete gasoline and diesel combustion with less production of carbon monoxide and unburnt hydrocarbons. It is proposed that KELEA from the activated fuels is transferred as a non-thermal kinetic energy to the fuel combustion products and that it contributes to the mechanical work of these products within an engine. The added kinetic energy may possibly be in the form of solitons. In any event, the data are sufficiently compelling to suggest that all fuels used in transportation should be KELEA activated.

\section{Acknowledgements}

Mr. James Osugi, president of Kiko Technology and Mr. John Graham, president of Dearborn Corp., kindly provided data relating to their respective devices. Tom and Bill Lang provided information on their Brown's gas device for automobiles. Dr. Derek Zupencic, president of HH2 Energy Corp., discussed his findings using hydrogen as a fuel additive (www.hydrolectricpower.com). Mr. Nobuyuki Azuma assisted with studies on HB-101. The Institute of Progressive Medicine is a component of MI Hope Inc., a non-profit public charity.

\section{Conflict of Interest}

None.

\section{References}

[1] Chaplin, M. (2006) Do We Underestimate the Importance of Water in Cell Biology? Nature Reviews Molecular Cell Biology, 7, 861-866. http://dx.doi.org/10.1038/nrm2021

[2] Martin, W.J. (2014) KELEA ${ }^{\mathrm{TM}}$ Activated Water-Enhancing the Alternative Cellular Energy (ACE) Pathway in Stealth Adapted Viruses; Alternative Cellular Energy (ACE) \& KELEA Activated Water. Author House, IN, 132-173.

[3] Martin, W.J. (2015) KELEA: A Natural Energy That Seemingly Reduces Intermolecular Hydrogen Bonding in Water and Other Liquids. Open Journal of Biophysics, 5, 69-79. http://dx.doi.org/10.4236/ojbiphy.2015.53006

[4] Martin, W.J. (2015) Methods of KELEA Activation of Water and Benefits in Health, Agriculture and Industry. Journal of Water Resource and Protection, 7, 1331-134. http://dx.doi.org/10.4236/jwarp.2015.716108

[5] Martin, W.J. (2015) Interacting Light Paths Attract KELEA (Kinetic Energy Limiting Electrostatic Attraction) and Can Lead to the Activation of Water. Open Journal of Biophysics, 5, 115-121.

http://dx.doi.org/10.4236/ojbiphy.2015.54010

[6] Martin, W.J. (2015) Interactive Electric Fields Can Attract KELEA (Kinetic Energy Limiting Electrostatic Attraction) and Can Lead to the Activation of Water. International Journal of Complementary \& Alternative Medicine, 1, Article ID: 00034.

[7] Martin, W.J. and Laurent, D. (2015) Homeopathy as a Misnomer for Activation of the Alternative Cellular Energy Pathway: Evidence for the Therapeutic Benefits of Enercel in a Diverse Range of Clinical Illnesses. International Journal of Complementary \& Alternative Medicine, 2, Article ID: 00045.

[8] Martin, W.J. (2015) Alternative Cellular Energy. A Unifying Concept in Complementary Alternative Medicine. International Journal of Complementary \& Alternative Medicine, 1, Article ID: 00022.

[9] Martin, W.J. (2015) Therapeutic Potential of KELEA Activated Water. International Journal of Complementary \& Alternative Medicine, 1, Article ID: 00001. http://dx.doi.org/10.15406/ijcam.2015.01.00001

[10] Martin, W.J. (2014) KELEA Activated Water Leading to Improved Quantity \& Quality of Agricultural Crops. Advances in Plants \& Agriculture Research, 2, Article ID: 00033.

[11] Martin, W.J. (2015) Improved Efficiency of Heat Exchange Using KELEA Activated Water. Open Journal of Energy Efficiency, 4, 36-43. http://dx.doi.org/10.4236/ojee.2015.42004

[12] Martin, W.J. (2008) Method of Generating Hydrogen in Gasoline Using an Enerceutical Product Added to Magnesium in a Hydrogen Permeable but Solute Impermeable Container. Patent Application Number 20100011657.

[13] Musmar, S.A. and Al-Rousan, A.A. (2011) Effect of HHO Gas on Combustion Emissions in Gasoline Engines. Fuel, 90, 3066-3070. http://dx.doi.org/10.1016/j.fuel.2011.05.013

[14] El-Kassaby, M.M., Eldrainy, Y.A., Khidr, M.E., Kareem, I. and Khidr, K.I. (2016) Effect of Hydroxy (HHO) Gas Ad- 
dition on Gasoline Engine Performance and Emissions. Alexandria Engineering Journal, 55, 243-251. http://dx.doi.org/10.1016/j.aej.2015.10.016

[15] Yilmaz, A.C., Uludamar, E. and Aydin, K. (2010) Effect of Hydroxy (HHO) Gas Addition on Performance and Exhaust Emissions in Compression Ignition Engines. International Journal Hydrogen Energy, 35, 1366-1372.

http://dx.doi.org/10.1016/j.ijhydene.2010.07.040

[16] Hicks, P. (2014) Ideal Gas Law 51 Success Secrets—51 Most Asked Questions on Ideal Gas Law—What You Need to Know. Emereo Pty Ltd. Brisbane, Australia, 50.

[17] Remoissenet, M. (1999) Waves Called Solitons: Concepts and Experiments. 3rd Edition, Springer-Verlag, Berlin, 327. http://dx.doi.org/10.1007/978-3-662-03790-4

\section{Abbreviations}

KELEA: kinetic energy limiting electrostatic attraction rpm: revolutions per minutes ppm: parts per million $\mathrm{km} / \mathrm{l}$ : kilometer per liter $\mathrm{CO}_{2}$ : carbon dioxide $\mathrm{CO}$ : carbon monoxide UHC: unburnt hydrocarbons mph: miles per hour gm: gram mm: millimeter cm: centimeter \%: percent 